\title{
A Blueprint for Building Online Reference Knowledge Bases
}

\section{Boris Bosančić}

Boris Bosančić is a Research Assistant in the Department of Information Sciences, Faculty of Philosophy, Josip Juraj Strossmayer University, in Osijek, Croatia. Submitted for review November 24, 2009; accepted for publication January 30, 2010.
Reference \& User Services Quarterly, vol. 50, no. 2, pp. 152-61

(c) 2010 American Library Association. All rights reserved.

Permission granted to reproduce for nonprofit, educational use.
This paper presents a theoretical framework for understanding the process of generating and storing knowledge from online reference service transactions. Terminology for this study has not been sufficiently developed in scholarly work, so this paper uses the phrase "online reference knowledge base" (ORKB) to denote a place for storing knowledge generated from online reference services. In addition to reevaluating the present role of ORKBs through interviews with experts and practitioners who are most closely linked to online reference services, the paper attempts to offer a blueprint of adequate principles and guidelines for the future development of ORKBs.

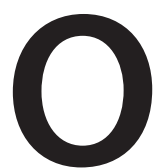

nline reference services emerged during the mid1990s as an extension of existing reference services in libraries. Today, online reference services represent a standard library service in a networked environment. They have added archival value because they provide a way to store communications between the reference librarian and the user, preserving generated knowledge and its repeated use in a search for new information. This archive of users' answered questions is often referred to as the "knowledge base" of the service, which is alluded to by the name of the largest online reference service in the world-QuestionPoint (www.oclc .org/questionpoint). That is why I use "knowledge base" here; however, the literature has not sufficiently explored this term. Neither the very concept of an existing online reference knowledge base (ORKB) nor the possibility of its development has been explored thoroughly. Therefore the purpose of this article is to question the current role of knowledge bases as an archive of users' answered questions in the context of online reference services, with the basic goal of establishing appropriate principles and guidelines for ORKBs' future development.

At the beginning of the article, I outline the concept of ORKBs as an archive of users' questions and answers. I will talk about frequent question card files, which is the precedent to the modern ORKB, after which I will discuss the current theoretical accomplishments in this area. In the practical sense, I will refer to QuestionPoint, and to the Croatian public libraries' Ask a Librarian service ("Pitajte knjižničare"), which I had at my disposal for analysis and research through their administrative interfaces. ${ }^{1}$ I explore the online reference services' standardization as 
well the presentation of the Digital Reference Electronic Warehouse (DREW) project promoted by R. D. Lankes and S. Nicholson, both online reference services experts. I conducted in-depth interviews with online reference service experts; I attempted to ascertain the experts' positions on the possibility of the development of ORKBs. On the basis of the conducted analyses and research, I will propose principles and guidelines for developing efficient ORKBs. Finally, I will suggest further research in this area.

\section{THE CONCEPT OF KNOWLEDGE BASES IN ONLINE REFERENCE SERVICES}

\section{Developing the Concept of Knowledge Bases in Reference Services: Frequent Question Card Files}

As far back as the nineteenth century, reference librarians' need to facilitate knowledge exchange between themselves led them to use special cards or card files, which were created and maintained mostly by volunteer reference librarians with the goal of storing information related to users' questions and librarians' responses. These librarians organized the card files either alphabetically or by subject and made them available to other reference librarians to answer similar requests in the future. The annotated information usually related to the discovered sources, that is, answers to certain questions, especially those repeatedly asked or those that demanded in-depth research. In addition, Anglo-American expert terminology often referred to frequently-asked-question card files by various names, such as "quick reference file," "query file," "useful reference file," "information file," "file of answered questions," "vertical file," etc. However, the names that became most commonly used are "frequent question card files" and "ready reference card files." 2

Although there is evidence of the existence of such card files in every library for more than a hundred years, their purpose, structure, and contents have not been sufficiently processed or represented in library-related literature. ${ }^{3}$ With the advent of information technology in libraries, some librarians have attempted to automate these card files. ${ }^{4}$ Perez characterizes frequent-question-andanswers card files as beta-test knowledge bases. ${ }^{5}$ There is no doubt that the frequent-question-andanswer card files can be viewed as a concept that precedes the emergence of ORKBs more than a century later.

\section{THE CONCEPT OF ORKBS AS AN ARCHIVE OF USERS' ANSWERED QUESTIONS}

The usual understanding of an ORKB is of an archive that contains answers to users' past questions. In the beginning of ORKB development in the mid-1990s, online reference services were no more than an ordered archive with questions and answers along with information regarding the time of query and the time necessary to give an answer. In the example of the Ask a Librarian service offered by the Croatian public libraries, it is clear that these are not knowledge bases but in fact "answered questions bases," or rather, "questions and answers bases." However, in the case of the QuestionPoint service, the archive of answered users' questions is explicitly referred to as a "knowledge base."

According to Peter Armenti, one of QuestionPoint's founders, an ORKB is a "searchable electronic archive of question and answer pairs as a support to the users' information needs." First, a knowledge base is built to save time. Questions that have already been answered are not answered again; instead, the answers are forwarded to the user automatically from the knowledge base. The other reason to develop such a base, according to Armenti, has to do with distributing reference librarians' knowledge as they participate in the project to answering users' questions. ${ }^{8}$ In this way, ORKBs begin to incorporate the purpose of another kind of knowledge base found in the field of knowledge management: knowledge distribution. Apart from that, it is worth mentioning that future explorations of the economic effects would be beneficial because setting up a questions-and-answers archive will surely contribute to significant savings in the business of a library.

Apart from being an electronic pair archive (question and answer), a knowledge base should also contain information regarding how a certain question was answered, including information about research techniques, strategies, sources, etc. Armenti offers the following advice to consider before building a knowledge base for an online reference service:

- Identify the target user group who will be using the knowledge base.

- Determine the goal or purpose of the knowledge base (e.g., saving time in answering previously answered user questions).

- Identify metadata types, which will make up the transaction entry in the knowledge base. 
- Create suitable documents that will contain instructions on how to search through the knowledge base.

- Constantly check every new idea brought to the reference librarian related to the design of the knowledge base and that can stem from everyday use of the existing questions and answers. ${ }^{9}$

In a 2005 work, Chen demonstrates best practices in the use of web technology to build a web-based system in which reference librarians can record their reference experience. ${ }^{10}$ This work is significant because the author treats such a knowledge base as not only a key component for online reference services as a separate system, but also as an aid in the reference librarians' work in the context of traditional reference services. Any reference service provider can find the reason for building such a system in everyday work with users, where users often ask questions that have been previously answered, but the provider is unable to remember the answer. In that sense, Chen sees particular advantages in building such knowledge bases for the following reasons:

- Time is saved for the reference librarian.

- The knowledge base becomes an apt tool for training new reference librarians.

- The knowledge base also becomes an archive containing the answered users' questions that is available to other users.

- The knowledge base thus develops into a significant component of the online reference service. ${ }^{11}$

Soon after the QuestionPoint service was established at the convention of the American Society for Information Sciences and Technology (ASIS\&T) in 2004, a panel debate was organized on the subject of reference services and knowledge bases. The panel was attended by Armenti as a representative of the Congressional Library and someone who was very closely connected to the development of the knowledge base for the QuestionPoint service; Boris Katz, founder of the question answering project START, who has also been involved in developing the system of the same name that answers users' questions; and Lankes and Nicholson, developers of DREW. DREW was actually a test knowledge base for online reference services, which was expected to be able to archive reference transactions from multiple electronic archives in certain Ask A Librarian services, on the basis of the previously agreed standard for archiving reference transactions. ${ }^{12}$ At that point, an unprecedented interest in the development of ORKBs was noted by other researchers. The future looked bright for ORKBs, and the panel gathered the most qualified experts to discuss the subject.

However, today we see a significant decrease in enthusiasm. The reasons for that should be sought primarily in the complexity of the demands that arise from building such a knowledge base, which requires a thoughtful and systematic approach. In addition, the statistic indicators from research conducted in 2008 show that users access knowledge bases much less than had been expected. ${ }^{13}$ This lack of use, however, can be explained by the fact that ORKBs have not yet developed to the point that they would offer satisfactory service to users. As for the panel debate, it presented experts-for the first timewith significant theoretic reaches in the area of ORKBs, which complemented the findings from practical work in setting up the knowledge base for the QuestionPoint service. It is worth pointing out the achievements of Nicholson and Lankes, who have united their ideas and published them in "The Digital Reference Electronic Warehouse (DREW) Project: Creating the Infrastructure for Digital Reference Research through a Multi-Disciplinary Knowledge Base."14 Because of that, as well as the efforts to utilize the results of the research in this particular enterprise, it is necessary to give this work special consideration.

\section{THE DREW PROJECT}

Nicholson and Lankes's article presents the efforts surrounding the DREW project, which built a large reference transactions base for the researchers. ${ }^{15}$ This knowledge base could be helpful in achieving a better understanding of the very processes that occur in the context of online reference services. However, in the very beginning of the research, Nicholson and Lankes became aware that the lack of a pattern was a problem: there was no standard used in archiving reference transactions in the existing knowledge bases, which made it impossible to examine transaction entries from multiple knowledge bases.

When online reference services were initially offered only locally (i.e., in the context of an individual institution), the need for technical standards was not so obvious. The need for standards arose when libraries began setting up cooperative online reference services. From then on, it is possible to view the digital reference space as abstract, consisting of a certain number of online reference services. ${ }^{16}$ Nicholson and Lankes predicted in that context that three elements would be particularly 
affected by this standardization procedure:

- the profile of the institution involved in the joint project of offering online reference services

- the protocols that would allow for the technical transaction between different services

- the metadata schema of the knowledge base that is derived from experience in transaction archiving

Based on the then up-to-date information, and as part of the DREW Project, the researchers focused on the final element that was to undergo standardization in the context of online reference services: specifying the metadata scheme of the knowledge base on the basis of the experience in archiving transactions. They used a survey of U.S. reference librarians that were involved in online reference service to find out which particular metadata those librarians considered necessary to include in a knowledge base. Then the researchers made the resulting metadata schemata compatible with the NISO standard, that is, with the NetRef protocol. ${ }^{17}$ The results of their research led the researchers to conclude that online reference services employees wanted to gather more information about the reference transactions than they previously did. ${ }^{18}$

The work I have mentioned is especially significant to online reference services becauseapart from the roles of users and reference librarians, that is, experts in charge of answering user questions - it also puts great emphasis on the role of the system administrator, who is behind the program solution, as well as the administrator in charge of maintaining the entire system (unless both roles are performed by a single person).

The first result of the DREW Project is Reference Extract (www.digref.org), a developing project described as "a search engine useful in exploring public archives of digital reference transactions." ${ }^{19}$ The purpose of this project is to build a credible, specialized search engine based on "reference authoring," a term used by Lankes, the most influential researcher in this field. Reference authoring denotes the "production of secondary artifacts (entries) by using (primary) reference interaction." ${ }^{20}$ In other words, the phrase "reference authoring is most closely linked to the building of knowledge bases for online reference services, but the more significant inclusion of this term into the discourse in the field is only expected in the future." Lankes explains reference authoring in terms of credibility, reference weighting, and transformation, which create a complex theoretical basis. ${ }^{21}$

\section{THE CONCEPT OF KNOWLEDGE BASES IN ONLINE REFERENCE SERVICES AS EXTENDING VIRTUAL REFERENCE COLLECTION}

An extended knowledge base for online reference services also encompasses a "links database" or extended virtual reference collection, a directory developed primarily on information sources used to search for answers to users' questions. The Ask a Librarian service offered by Croatian public libraries, along with answering user questions, also puts in a lot of effort to build an extended virtual reference collection. This collection is really a directory containing electronic information from the Internet, which has been divided into a sequence of subdirectories according to subject matter.

However-except for the knowledge management field, in which knowledge bases are considered "knowledge treasuries" specific to one particular organization - the extended concept of knowledge bases that also encompass consulted information sources in finding answers receives little attention in the available literature. Knowledge bases in the field of knowledge management are actually understood in a broader sense, and they encompass the sources and tools that contribute to the collection of knowledge all in one place. When understood so broadly, they possess no sharper demands for their construction. Such a knowledge base in its beginning is nothing more than a shared directory that contains all the important documents belonging to an organization. What makes this directory different from any other is its purpose: the directory is designed to solve a certain problem specific to that field.

In this work, however, I wish to emphasize those points that make it possible to connect an extended virtual reference collection to the ORKBs. One such point is the field of reference transaction, which stores information about the sources consulted in replying to user questions. However, there are many software solutions for online reference services, among which is the module for the QuestionPoint knowledge base service, where the field that is used for storing the consulted information sources to answer user questions is not functional in terms of field functionality inside a database. This means that it is not repeatable for every separate source; instead, all the sources inside a field ( e.g., a cell or field in the database table) are divided by a colon. For that reason, the consulted information sources are not searchable in relation to the goal of finding out which source was used for what queries. The same software characteristics 
appear in the software programming environment of the Ask a Librarian service from the Croatian public libraries. The information module in the answer field only adds information sources one underneath the other according to the prearranged rules of quoting information sources. In addition, the quoted information sources in the reply are usually divided into three types: books, magazines, and network (online) sources. However, all these types of information can be extremely helpful if they become part of the standardized entry in a searchable reference transaction. On the other hand, virtual reference collections, indexes, and the like Have long been a part of the more common online reference services, such as the Internet Public Library (www.ipl.org).

Analysis of the extended virtual-referencecollection concept in the examples of the QuestionPoint and Ask a Librarian services prompted consideration of the possibilities of a larger integration of extended virtual reference collections and ORKBs.

\section{EXPLORING THE POSSIBILITIES OF DEVELOPING THE CONCEPT OF ORKBS}

\section{The Research's Purpose, Goals, and Implementation}

An ORKB belongs to what is still an insufficiently explored area, where no basic agreement regarding terminology has yet been reached. That is why, in the exploratory part of the work, I use a qualitative method of conducting in-depth interviews with experts closely linked to online reference services to ascertain attitudes regarding the future development of knowledge bases for that kind of service. I bypass quantitative methods in research because the practical use of knowledge bases of online reference services by reference librarians and users is insufficient, and any significant statistic indicators about knowledge base use (except in case of the global knowledge base of QuestionPoint) are lacking, which could be subjected to an in-depth scientific analysis. ${ }^{22}$ On the other hand, this essay's primary goal - the development of principles and guidelines for creating knowledge bases of online reference services —naturally points to checking the attitudes, doubts, and suggestions of experienced and responsible experts in the field of online reference services.

The research's purpose is therefore reflected in the questioning of experts' attitudes regarding the current role of ORKBs, as well as discovering suitable principles and guidelines for their future development. The essential goal of the research is to explore, in a general sense, ways of storing produced knowledge in the context of online reference services, or rather the conditions under which the form of storage can be made more effective for reference librarians in answering future questions as well as for further research. I based my research on the interview method.

For the interviews, I selected people who usually bear great responsibility in the work of reputable online reference services (four participants are involved in the QuestionPoint service and one is involved in the Ask a Librarian service of the Croatian public libraries). In three of the cases, I interviewed the managers of online reference services. In one case, I interviewed the section manager for user services inside an integrated library system that is directly involved in the QuestionPoint service. In another case, I interviewed an OCLC researcher who is closely involved in the development of the knowledge base for the QuestionPoint service. ${ }^{23}$

In the first set of questions, I asked the participants to confirm the assumption that online reference services (their knowledge bases) are used to store knowledge derived from the communication between users and reference librarians during the time that was needed to search for the answer to the question. In this part of the conducted interviews, most participants responded in the affirmative. However, in the second set of questions, which had to do with participants' statements regarding their practical experiences with the service's knowledge base, most of the participants made it clear that their use of the knowledge base is minimal or nonexistent. One exception was a participant from OCLC, who stated that she used the knowledge base on a daily basis but is required to use it as part of her job (she is the editor of the global knowledge base for the QuestionPoint service). Unfortunately —with the exception of the OCLC employee, who is an administrator of the global knowledge base of the QuestionPoint service - in answering the question, "Do you possess any statistic indicators regarding the use of the reference transactions archives? If so, can you state them?" again, the other participants were unable to deliver any acceptable form of statistics for the use of their ORKBs.

The third set of questions required the participants to reflect on the principle of building efficient ORKBs; the questions explored the desirable experience of the participants in the use of the knowledge base. A question first asked the participant to provide an affirmative answer and then to count all the benefits that the librarians and users can gain from the ORKBs. For example, if the participants 
answered that the ORKB could save reference librarians' time, this could very easily turn into a principle that says that ORKBs need to be developed toward that purpose. I designed the second question to extrapolate a minimal set of metadata that would be stored in reference transactions, with the initial set of metadata that coincided with the metadata set offered by Lankes and Nicholson in their research. The metadata set selected by the participants is shown in table 1 highlighted in gray.

As shown in table 1, all participants agreed that the metadata under numbers 5, 15, and 17 should become an integral part of any reference transaction. In relation, the question-and-answer texts and other information sources that aided in finding the answer were the expected choices of the participants. It is interesting that the same occurred for metadata number 5 (query categorization by the user through free-form subject guidelines). Finally, the participants were asked to offer their own ideas for creating principles of ORKB development. Thus, according to the participants' answers, these are the elements that are important for the development of ORKBs: application of standard methods in searching the answers to user questions, user-friendliness and searchability, avoiding classifications that are hard for the user to understand, use of uniform classifications, recognition of librarians' motivations, and follow-up processing of questions and answers.

In the following set of questions, I asked the participants to test guidelines for improving the functionality of ORKBs on the basis of information that could be extrapolated from the up-to-date expert literature or that were otherwise suggested by me. I also asked them to leave their comments if they disagreed with the proposed guidelines. The first question was "Do you support automatization of the process of answering previously answered questions?" Only Participant 4 gave a negative answer because she thought that "automatization is unnecessary because there are now two identical user queries; besides, information sources change and are updated, and in the case of taking ready answers, they need to be checked, complemented, corrected, and always sent as new ones." Participant 3 responded that "automatization may become necessary only in the future," while Participant 5 said that "automatization is unnecessary, but could be useful." The second question was "Do you support finding a way to store the strategies used to find answers?" to which four participants gave a positive response. Only Participant 5 thought "reference librarians should not be additionally burdened by more work, which is exactly what this guideline would accomplish." To the last in that set of questions, which read "Do you support the integration of online reference knowledge bases with extended virtual reference collection?" four participants agreed on a positive response. Only Participant 2 disagreed; she felt that the "users should not consider where the sources of information for their queries have been used before."

The final interview question deals with participants' opinions regarding the future development of ORKBs. Because of the philosophical connotations involved, the question was exceptionally difficult for the participants, which is why some refused to answer it: they considered themselves either not qualified in the field or not sufficiently informed on the matter. One participant did not think that ORKBs would have a significant effect on future data storage, but he did seem to think that their significance might increase in the future and felt that we do not have enough experience in working with them to be able to predict their development. A participant from OCLC stated that, as much as she felt unsure whether the term "knowledge base" should remain in use or not, she had no doubts about the necessity of ORKB's future development. As for the guidelines for development of ORKBs, she emphasized working on developing a mechanism for searching double entries (questions with identical or different answers), introducing interactions with the user through added information fields, the possibility of deleting entered content for the users, and developing a more user-friendly search engine for reference transaction entries.

\section{BASIC PRINCIPLES AND GUIDELINES FOR BUILDING ORKBS}

\section{Principles}

Principles for building ORKBs would preferably be observed by experts involved both in building ORKBs (developers, metadata editors, librarians who enter the data) and in monitoring input of new information into them (administrators or knowledge base editors). For example, in the QuestionPoint service, this role is performed by one of the participants, who cleans out semantic and typographical errors and eliminates all redundancies in the record.

Whether you are developing a local ORKB within an online reference service or a shared ORKB between multiple online reference services, I suggest the following principles:

\section{Saving the Reference Librarian Time}

In this sense, I refer to the foundational usefulness 
Table 1. Minimal Metadata Set of the Reference Transaction as Selected by the Participants

\begin{tabular}{|c|c|c|c|c|c|c|c|}
\hline \multirow[b]{2}{*}{ No. } & \multirow[b]{2}{*}{ Metadata of the reference transaction } & \multicolumn{5}{|c|}{ Participants } & \multirow[b]{2}{*}{$\%$} \\
\hline & & 1 & 2 & 3 & 4 & 5 & \\
\hline 1. & Name of online reference service & & & & & + & 20 \\
\hline 2. & Education level of users requesting query ${ }^{24}$ & & + & & & + & 40 \\
\hline 3. & Postal code in user's address & & & & & & 0 \\
\hline 4. & User's country & & & & & & 0 \\
\hline 5. & Query categorization by the user through free-form subject guidelines & + & + & + & + & + & 100 \\
\hline 6. & Query categorization by the reference librarian & & + & & + & + & 60 \\
\hline 7. & Query date & & & & & + & 20 \\
\hline 8. & Query time (standardized) & & & & & & 0 \\
\hline 9. & Previously consulted sources & + & & + & & + & 60 \\
\hline 10. & Has the query been forwarded to another service? & & & & & + & 20 \\
\hline 11. & Name of service that the query was forwarded to & & & & & + & 20 \\
\hline 12. & The role of the person answering the query (librarian or field expert) & & & & & & 0 \\
\hline 13. & Date of reply & & + & + & + & & 60 \\
\hline 14. & Time of reply & + & & & & & 0 \\
\hline 15. & Information sources that helped in the search for the answer & + & + & + & + & + & 100 \\
\hline 16. & $\begin{array}{l}\text { Answer type (text, query clarification request, no answer found notifi- } \\
\text { cation, etc.) }\end{array}$ & & & & & + & 20 \\
\hline 17. & Query and answer texts from corresponding fields in the web form & + & + & + & + & + & 100 \\
\hline 18. & $\begin{array}{l}\text { Text, i.e. e-mail body text (if communication relating to the online } \\
\text { reference services was conducted via e-mail) }\end{array}$ & & & & & + & 20 \\
\hline 19. & Transcript of chat between the user and the reference librarian & & & & & + & 20 \\
\hline 20. & $\begin{array}{l}\text { Type of reference transaction (depending on the method of communi- } \\
\text { cation: e-mail, web forms, chat, etc.) }\end{array}$ & & & & & + & 20 \\
\hline 21. & $\begin{array}{l}\text { Adjusted field for entering user data, such as classifying users with } \\
\text { regard to their local significance inside a service }\end{array}$ & & & & & + & 20 \\
\hline 22. & $\begin{array}{l}\text { Adjusted field for entering query data, such as classifying the query in } \\
\text { regard to its local meaning inside a service }\end{array}$ & + & & & & & 20 \\
\hline 23. & $\begin{array}{l}\text { Adjusted field for entering information for the answer, such as clas- } \\
\text { sifying the answer in terms of its local meaning inside a service }\end{array}$ & + & & & & & 20 \\
\hline
\end{tabular}

of the knowledge base; if the base does not save time for the reference librarian, the knowledge base's purpose has been missed. Apart from the participants, other experts that I mentioned in the theoretical part of the essay also point out this necessary characteristic of ORKBs. ${ }^{25}$ However, a study conducted by Rumbaugh showed that librarians tend to think that entering the query into the ORKB is actually time-consuming because it requires entering additional metadata. ${ }^{26}$

\section{Saving Users'Time}

Here I am also considering the ORKB's users, but the principles are different and are stated separately because their realization requires different procedures. I here refer primarily to such cases as when a user asks the service a question to which the knowledge 
base already has an answer. In that case, the user needs to be encouraged to search for the answer in the knowledge base first because it is perhaps not necessary to ask the reference librarian on duty.

\section{Education of Reference Librarians}

The role of an ORKB in the education of reference librarians is to allow the librarians to analyze the ORKB's stored reference transactions. This will teach reference librarians about answer formulation, answer-searching strategies, consistency, and quality standards in replying to users' questions, etc. ${ }^{27}$

\section{Users' Information Literacy}

The principle of users' information literacy coincides with the principle of educating reference librarians. There is, however, no mention of a special form of educating users in the context of ORKBs. In fact, the user learns through the reference-transaction entries stored in the ORKB to "sketch out survival strategies" by suggesting "the right ways of asking questions." 28

\section{Possibility of Evaluating a Service}

If the ORKBs stick to this principle, the software should enable the monitoring of statistic indicators regarding the use of the service (the QuestionPoint service already does this). ${ }^{29}$ Apart from monitoring and evaluating the work of a particular institution in the context of a joint project of an online reference service, the utilization of a statistic module should enable monitoring and evaluation of the work of each reference librarian.

\section{Service Standardization \\ (entries in the ORKB)}

I have already talked about the standardization of entries inside ORKBs. The purpose of this procedure, apart from allowing access to entries from multiple knowledge bases, is to enable further scientific research into the concept of ORKBs. ${ }^{30}$ The importance of this is seen in the insufficiently structured concept of founding the ORKBs. For example, should an archive of responses to users' questions truly be considered a knowledge base considering the use of the same term in other fields, such as knowledge management?

\section{User-Friendly Interface}

The principle of the user-friendly interface refers both to the characteristic of easily searching
ORKBs, actually accessing the information sought, and-for the reference librarian-adding new entries. This principle emerged from answers provided by the interview participants.

\section{Application of Standard Methods of Searching}

This principle correlates to the suggested guideline for data storage strategies in the reference librarians' search for the answer to the question. If an adequate storage method were found, it would open up a way to further standardize the service and it would make it possible to standardize the search procedure itself by allowing an answer to a specific question to be sought. At the very least, this principle would bring the benefit of the ability to share the applied searching methods between reference librarians. On the other hand, the application of this principle would at first require additional involvement by the reference librarian, which would be contrary to the time-saving principle.

\section{Guidelines}

Unlike the principles, the guidelines for building ORKBs prescribe specific steps or procedures that need to be taken to increase the efficiency of ORKBs. In relation to that, as previously stated, the fourth theme unit of questions from the interview offered the participants the choice to accept or decline three guidelines for building ORKBs. Since most of the participants accepted the suggested guidelines, they are listed first here. On the other hand, the answer to the question whose purpose was to determine the minimal metadata set that the ORKB should possess in its work is also understood as one of the guidelines in the development of knowledge bases.

The following are possible guidelines for building ORKBs (whether they are local or shared knowledge bases):

\section{Automation of Answering Previously Answered Questions}

Most of the discussion regarding this procedure has been debated, even among the participants themselves (60 percent agreed). Not only does this guideline satisfy the time-saving principle for the reference librarian, but it also links closely the field of online reference services and question answering systems (systems for automatic query response). In addition, the guideline affirms and connects the librarian with the latest technological 
achievements. Aside from automating the response procedure for previously answered questions, the ability to redirect users to a question in the ORKB similar to their own would be most welcome. This guideline for ORKBs includes a system for automatic responses to less demanding queries, which would primarily be beneficial for users, but also for librarians.

\section{Storage Strategy for Finding Answers by Reference Librarians}

This guideline encompasses information storage related to search strategies in Internet search engines, using the reference collection in the library or another adequate source for answering user queries. It is important to emphasize that this guideline serves to "store" the experience of reference librarians gathered during their work and make this experience available to other librarians. This guideline, more than any other, is connected to the identical efforts of the knowledge management community in attempting to transform implicit knowledge into explicit knowledge of the employee or librarian. ${ }^{31}$ The QuestionPoint service, through its Ask a Librarian module, currently makes it possible to monitor transactions between reference librarians and users because one can register any demand asked during the transaction, whether by the reference librarian or by the user (e.g., a clarification request). This characteristic of the QuestionPoint service helps realize the storage-strategy guideline because it outlines briefly the procedure by which the user's question is answered.

\section{Integrating ORKBs and an Extended Virtual Reference Collection for Information Sources}

The Croatian public libraries' Ask a Librarian service has already implemented this guideline, and there have been some signs that those behind the QuestionPoint service have also considered this possibility (Participant 3 from OCLC thinks that such integration should be achieved with WorldCat, the world's largest library catalog, developed by OCLC) ${ }^{32}$ Raising the reference transactions to the level of a knowledge base, in theory, is of extreme importance. In this way, links are established that are analogous to the ones in expert knowledge systems bases that belong in the field of artificial intelligence, or rather we could say that, for each information source registered in the extended virtual reference collection through a growing number of answered questions, its own "knowledge" begins to grow. Of course, this implies further questioning in the future.
Utilization of a Standardized Minimal

Metadata Set in the Entry of the Reference Transaction

In the in-depth interviews, I wanted to emphasize the metadata set that an ORKB should minimally store in its work, which should make it more efficient than knowledge bases that select other metadata. Participant selection (more than 50 percent) construed a requested metadata set, which is shown in table 1 . With this metadata set, the guideline encompasses the demand for its standardization, that is, an alignment with the standardization principle of the service (entry in the knowledge base).

\section{CONCLUSION}

By questioning the validity of the term "knowledge base" for the archive of responses in the context of online reference services, I attempted to suggest principles and guidelines for the services' future development. Current theoretical achievements in the field have been analyzed with special regard for the work of Armenti, Chen, and particularly Lankes and Nicholson. However, the most space was given to reflections on the QuestionPoint service and the Ask a Librarian service by Croatian public libraries, which I have been able to access through the administrative section of the interface. Special attention was also given to the process of standardization of the service as a whole, which has been recognized as key to the future development of ORKBs.

The research aspect of this work utilized the qualitative method of conducting in-depth interviews with people intimately involved in online reference services, thus attempting to come up with principles and guidelines for the future development of the ORKBs. I suggested principles for time-saving in the work of reference librarians and patrons, for the education of reference librarians, for the information literacy of users, for the evaluation of the service, for the standardization of entries in the knowledge base, for the development of a user friendly interface, and for the application of standard methods of searching for the answers to users' questions.

As for guidelines, I suggested the following: automating the procedure for answering previously answered questions, storing answer-finding strategies by reference librarians, integrating ORKBs and extending virtual reference collection for information sources, and using a standardized minimal metadata set for reference transactions (shown in table 1). 
In conclusion, through the realization of all the principles and guidelines offered in this paper, ORKBs can be brought much closer to reaching their full potential, whether they are considered to be knowledge bases or just archives of responses to users' past questions at this stage of development. In this sense, a reevaluation of the term "knowledge base," as used by the QuestionPoint service for their existing reference transaction archives, would most certainly be very welcome as a subject of future research.

\section{References and Notes}

1. Knjiznica.hr: Pitajte knjižničare, "O projektu 'Pitajte knjižničare," www.knjiznica.hr/pitajte-knjiznicare/ projekt (accessed Nov. 15, 2009).

2. Smiti Gandhi, "Knowledge Management and Reference Services," The Journal of Academic Librarianship 30, no. 5 (Sept. 2004): 368-81.

3. Ibid., 375 .

4. Joy Thomas and Stephen P. Sottong, "Automating Your Ready Reference File," Reference Services Review 22, no. 1 (Spring 1994): 89-93.

5. Ernest Perez, "Knowledge Management in the Library-Not," Database Magazine 22, no. 2 (Apr.May 1999): 75-78.

6. Knjiznica.hr: Pitajte knjižničare.

7. Peter Armenti, "Building a Knowledge Base: Justifications, Challenges, and the Library of Congress Experience" (presented at the Virtual Reference Desk Conference, San Antonio, Nov. 17-18, 2003).

8. Ibid.

9. Ibid.

10. Jiangping Chen, "Record Keeping and Collection Building: Establishing Your Own Knowledge Base for Reference Service" (presented at the Texas Library Association 2005 Annual Conference, Austin, Apr. 5-8, 2005).

11. Ibid.

12. Peter Armenti et al., "Reference Services and Knowledge Bases: When is Help Helpful? (SIGs STI, LT and USE): Panel Discussion" (presented at the ASIS\&T 2004 Annual Meeting, Providence, R.H., Nov. 13-18, 2004).

13. Paula Rumbaugh, "Information Management in Today's Library Reference: Does the Knowledge Base Fill the Bill?" (presented at Libraries in the Digital Age, Dubrovnik and Mljet, Croatia, June 2-6., 2008), www.ffos.hr/lida/datoteke/LIDA2008-Rumbaugh_ monday.pdf (accessed Nov. 15, 2009).

14. Scott Nicholson and R. David Lankes, "The Digital Reference Electronic Warehouse (DREW) Project: Creating the Infrastructure for Digital Reference Research through a Multi-Disciplinary Knowledge Base," Reference \& User Services Quarterly 46, no. 2 (2006): 45-59.

15. Ibid.

16. R. David Lankes, "Emerging Standards for Digital Reference: The Question Interchange Profile," in Implementing Digital Reference Services: Setting Standards and Making It Real, ed. R. David Lankes et al. (New York: Neal-Schuman, 2003): 85-93.

17. NISO: Workshop Final Report, www.niso.org/news/ events/niso/past/netref (accessed Nov. 15, 2009);
Networked Reference Services: Question/Answer Transaction Protocol, www.niso.org/publications/ tr/TR04-NetRefQAProtocol.pdf (accessed Nov. 15, 2009).

18. Nicholson and Lankes, "The Digital Reference Electronic Warehouse," 55.

19. R. David Lankes and Scott Nicholson, "Reference Extract: Extending the Reach of Digital Reference through Collaborative Data Warehousing," TCDL Bulletin 2, no. 1 (2005), www.ieee-tcdl.org/Bulletin/ v2nl/nicholson/nicholson.html (accessed Nov. 15, 2009).

20. R. David Lankes, "Reference Authoring," http:// quartz.syr.edu/rdlankes/Presentations/2006/iSchool .pdf (accessed Nov. 15, 2009).

21. Ibid.

22. Rumbaugh, "Information Management."

23. The following experts have been interviewed (in the tables that show the research results, the participants have been marked by numbers 1 to 5 ):

Participant 1: Marina Mihalić, head of the Central Information Service of the National and University Library in Zagreb.

Participant 2: Romana Muhvič Šumandl, head of the Customer Service COBISS in Maribor, Slovenia (http://home.izum.si/izum/qp).

Participant 3: Paula Rumbaugh, member of the QuestionPoint development team from OCLC (www. oclc.org) with emphasis on the development on the global knowledge database of the service.

Participant 4: Zdenka Sviben, main coordinator of the Ask a Librarian project by the Croatian public libraries (www.knjiznica.hr/pitajte-knjiznicare).

Participant 5: Gorazd Vodeb, former head of the information service in the National and University Library in Ljubljana (www.nuk.uni-lj.si/), a facility directly involved with the QuestionPoint service.

24. It is necessary to distinguish between the education level of the user with the query and of the user who needs an answer. For example, parents often ask questions on behalf of their children, which makes it important to adjust the answer to the child's educational level instead of the parent's.

25. Chen, "Record Keeping and Collection Building"; QuestionPoint: Overview, www.questionpoint. org/support/documentation/gettingstarted/questionpoint_overview.pdf (accessed Nov. 15, 2009); Gandhi, "Knowledge Management," 375; Armenti, "Building a Knowledge Base."

26. Rumbaugh, "Information Management."

27. Chen, "Record Keeping and Collection Building."

28. I described the need for the informational education of users in the context of online reference services with the help of Božica Dragaš-Matijević in "The Role of 'Ask a Librarian' Service in Promoting Information Literacy," (presented at the 14th European Conference on Reading, Zagreb, Croatia, July 31-Aug. 3, 2005), www.hcd.hr/datoteke/Zagreb_Conference_ Proceedings.pdf (accessed Nov. 15, 2009).

29. Rumbaugh, "Information Management."

30. Nicholson and Lankes, "The Digital Reference Electronic Warehouse," 45.

31. Gandhi, "Knowledge Management and Reference Services," 374.

32. Bosančić and Dragaš-Matijević, "The Role of 'Ask a Librarian."” 